Journal of Animal and Veterinary Advances 10 (16): 2095-2098, 2011

ISSN: $1680-5593$

(C) Medwell Journals, 2011

\title{
Polymorphism Identification of IRF 6 Gene and it Associate with Immune Trait in Three Pig Populations
}

\author{
Zhihua Cai, Like Wang, Deyi Liu, Shenghe Li, Xunsheng Pang and Yuxin Cheng \\ College of Animal Science, \\ Anhui Science and Technology University, 233100 Fengyang, P.R. China
}

\begin{abstract}
In this study, researchers chose the Interferon Regulatory Factor 6 (IRF6) gene as a candidate gene to evaluate its effect on porcine immune traits. Using the PCR-RFLP analysis and sequencing, a SNP (HQ026023:1383 G>C) in exon7 of IRF6 gene was detected. In addition, a further analysis of SNP genotypes associated with immune traits including IFN- $\gamma$ and IL10 concentrations in serum was carried out in three pig breeds including Large White, Landraces and Chinese indigenous breed Dingyuan Black pig. Results showed that the SNP of IRF6 gene effects on level of IFN- $\gamma$ and IL10 (day 20) in serum presented highly significances $(\mathrm{p}=0.0264 ; \mathrm{p}=0.0238)$ and as for the ratio of IFN- $\gamma$ to IL10 (day 20) in serum, the p-value was 0.0341 which also achieved a significant level. All the results could possibly indicate that the IRF6 gene should be regarded as a molecular marker gene for genetic selection associated with these immune traits in the pig breeding program.
\end{abstract}

Key words: Pig, IRF6 gene, polymorphism, PCR-RFLP, association analysis, China

\section{INTRODUCTION}

Interferon Regulatory Factors (IRFs) are a family of transcription involved in a pathway of interferoninducible genes regulation, viral response, cytokine signaling, cell growth regulation as well as hematopoietic development (Nguyen et al., 1997; Taniguchi et al., 1995). This $I R F$ gene family consists of nine members encoding transcription factors that share a highly conserved helix-turn-helix DNA-binding domain and a less conserved protein-binding domain (Taniguchi et al., 2001). Most IRFs play important roles in regulating the expression of IFN- $\alpha$ and IFN- $\beta$ after viral infection. Besides to the knowledge, the mutations of IRFG gene have been proved to cause human Van der Woud Syndromes (VWS). Owning to the drivers and potent effects of IRFs on the immune system, researchers suggested that the IRFs could be important marker genes for porcine immune response and disease susceptibility.

It is known that cytokines are important mediators during the immune responses and vary with health and disease status. IFN- $\gamma$ is critical for innate and adaptive immunity against viral and intracellular bacterial infections and also vital for tumor control (Schoenborn and Wilson, 2007). As for IL-10 which has pleiotropic effects in immunoregulation and inflammation down-regulating the expression of Thl cytokines, MHC class II antigens (Redpath et al., 1999; Lohoff and Mak, 2005). Different levels of these immune traits and their ratios in serum among individuals under same conditions could provide evidences for genetic control. According to this, identifying these genes and their potential functional mutation on these immune traits may supply a straightforward insight that work to improve immune capacity in pigs.

Considering the influences on IFN immune response and cytokines signaling pathway of IRF6 gene, we investigated polymorphisms of $I R F 6$ gene in all exons region in pigs and then performed an association analysis between the SNP and immune traits (IFN- $\gamma, \mathrm{IL}-10$, IFN- $\gamma / \amalg-10)$ in serum to estimate the possible effect of the IRF6 gene in three pig populations.

\section{MATERIALS AND METHODS}

Animal sources and samples: Animals were obtained from 3 pig breeds including Large White pig (94), Landrace (87) and Dingyuan Black pig (71) containing 252 piglets in animal populations. Among them, Large White pigs and Landrace were from the experimental farm of the Institute of Animal Sciences, Chinese Academy of Agricultural Sciences, Beijing, China. While Dingyuan Black pigs were provided by breeding stock farm in Dingyuan county, Anhui province, China. Blood samples were collected from each piglet 1 day before the vaccination (day 20) and then injected into VACUETTE ${ }^{\circledast}$ Serum Clot Activator tubes. DNA was extracted from the ear tissue samples of all pigs.

Corresponding Author: Cai Zhihua, College of Animal Science, Anhui Science and Technology University, 233100 Fengyang, P.R. China 
Table 1: Specific primers used for SNP identification of the porcine IRF6 gene

\begin{tabular}{|c|c|c|c|}
\hline Fragments & Primers sequence $\left(5^{\prime} \sim 3^{\prime}\right)$ & Product size (bp) & Annealing $\operatorname{Tm}\left(\mathrm{X}^{\circ} \mathrm{C}\right)$ \\
\hline \multirow[t]{2}{*}{ IRF6-Exon1 } & TGAGGGAGCTGGAAAACA & 243 & 60.0 \\
\hline & CAGATCATGGCCCTCCAC & & \\
\hline \multirow[t]{2}{*}{ IRF6-Exon2 } & TTCGTAAGCGAGGCAATTTT & 300 & 59.5 \\
\hline & GGCAGTTTCCTGTCTTCCAG & & \\
\hline \multirow[t]{2}{*}{ IRF6-Exon3 } & TGATGTTCAGGAAGGGGAA & 160 & 59.0 \\
\hline & AGGCCTGTGCATCTGTTTCT & & \\
\hline \multirow[t]{2}{*}{ IRF6-Exon4 } & GCAGAAGGTGGACAGGAAA & 255 & 59.4 \\
\hline & GCTCACCCACATCCTTGTCT & & \\
\hline \multirow[t]{2}{*}{ IRF6-Exon5 } & CAGTTCCCACCATCCATCTT & 400 & 59.8 \\
\hline & TTCAGTACCGTGGGAAGGA & & \\
\hline \multirow[t]{2}{*}{ IRF6-Exon6 } & AAGGCCAAGAGATGTTGAC & 155 & 60.5 \\
\hline & GATCTTATCGCCCACCAGAA & & \\
\hline \multirow[t]{2}{*}{ IRF6-Exon7 } & TGAAGTCATCAAGGCAGA & 232 & 59.6 \\
\hline & GTGGCGCGAATGATCTATG & & \\
\hline
\end{tabular}

Measurement of immune traits: Researchers use a commercial ELISA kit (Biosource, Carlsbad, California) to measure the immune traits including IFN- $\gamma$ and $\amalg-10$ concentration in each serum sample according to the manufacturer's instructions. All samples were arranged randomly in each plate and been used to calculate IFN- $\gamma$ and IL-10 concentrations based on a standard curve.

Polymorphism detection and PCR-RFLP: Genomic DNA was abstracted from the ear tissue sample using phenol/chloroform extraction and ethanol precipitation (Sambrook et al., 1989). Using the software Oligo 6.0, seven specific primers spanned seven corresponding exons region of the IRF 6 gene were designed based on the cloned porcine IRF6 genomic DNA sequence (GenBank accession number: HQ026023) (Table 1).

The PCR was carried out in a total volume of $25 \mu \mathrm{L}$ including 50-80 ng of template DNA, 10 pmol of each primer, $250 \mu \mathrm{M}$ dNTPs, $2.5 \mu \mathrm{L} 10 \times$ PCR buffer (with $\mathrm{MgCl}_{2}$ ) and $1.5 \mathrm{U}$ Taq polymerase (TaKaRa Biotechnology, China) and performed in a MJ Research PTC-200 Thermal Cycler (BIO-RAD, USA). The relevant reaction procedure was as follows: initial denaturation at $94^{\circ} \mathrm{C}$ for $5 \mathrm{~min}$ followed by 30 cycles of denaturation at $94^{\circ} \mathrm{C}$ for $1 \mathrm{~min}$ then annealing at $\mathrm{X}^{\circ} \mathrm{C}$ for $40 \mathrm{sec}$ ( $\mathrm{X}$ was shown in Table 1) and extension at $72^{\circ} \mathrm{C}$ for $1 \mathrm{~min}$ with a final extension step at $72^{\circ} \mathrm{C}$ for $5 \mathrm{~min}$.

Aftr directly sequencing for PCR fragments, the detected sequences were aligned based on the DNAMAN software (Version 5.2.2) aimed to identifying the mutation site. Results showed a G/C mutation was found in exon7 of IRF6 gene after comparing the obtained sequences in the three pig populations. Researchers then genotyped the polymorphic sites using the PCR restriction fragment length polymorphism (PCR-RFLP) method. As a result, a number of 252 DNA samples from three animal breeds (Landrace, Large White and Chinese indigenous breed Dingyuan Black pig) were genotyped and the allele frequencies were also calculated for each breed.
Association analysis: In the end, researchers implemented an analysis of the genotypes of the SNP associated with immune traits according to the following mixed models using in SAS9.13 software:

Where:

$$
\mathrm{Y}=\mathrm{X} \beta+\mathrm{Zb}+\mathrm{e}
$$

$\mathrm{Y}=$ The vector of phenotype for immune traits analyzed $\mathrm{X}=$ The design matrix for fixed effects

$\beta=$ The vector of fixed effects parameter including breed, ELISA plate effect and genotype effect

$Z$ = The design matrix of random animal effects

$\mathrm{b}=$ The mixed vector of random component including sires effect and dam effect within sires

$\mathrm{e}=$ The vector of residual effect

\section{RESULTS AND DISCUSSION}

SNP identification and genetic variation analysis: An $\mathrm{SNP}$ (HQ026023:1383 G>C) in exon7 of the porcine IRF6 gene was detected in the comparisons of sequence among three pig population meanwhile three corresponding genotypes were also clearly obtained (Fig. 1). This SNP (HQ026023:1383 G>C) is not missense mutation or to induce amino acid substitution. In addition, a total of 252 DNA samples obtained from animal populations were genotyped along with the determination of allele frequencies for each breed (Table 2). While for the genetic variation analysis there can know that there existed no significant differences between the allele frequencies among three pig populations. For another, it was obviously that the allele $G$ represented dominant than other alleles in three detected breeds. In contrast, the allele $\mathrm{C}$ had lower frequencies and $\mathrm{CC}$ genotype was not fund in Chinese indigenous breed Dingyuan Black pig.

Association analysis of immune traits and SNP genotypes: After the aforementioned research, researchers performed an association study to confirm whether the 


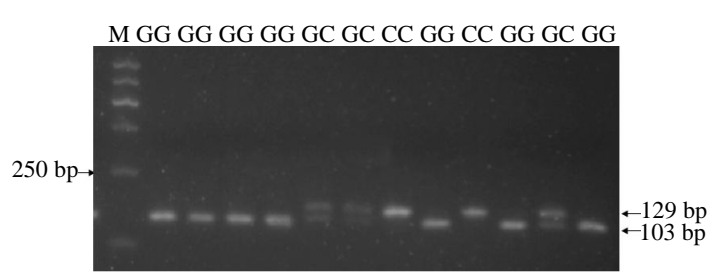

Fig. 1: PCR-RFLP analysis of the porcine IRF6 gene. Lane $M$ is DL2000 DNA molecular weight marker; Lane GG, GC and CC represent different genotypes

Table 2: Genotype frequencies and allelic frequencies of the IRF6 gene determined by PCR-RFLP in three pig populations

\begin{tabular}{|c|c|c|c|c|c|c|}
\hline \multirow[b]{2}{*}{ Breed } & \multicolumn{4}{|c|}{ Genotype frequencies } & \multicolumn{2}{|c|}{ Allele frequencies } \\
\hline & Number & GG & $\mathrm{GC}$ & $\mathrm{CC}$ & $\mathrm{G}$ & $\mathrm{C}$ \\
\hline Large white & 94 & 58 & 25 & 11 & 0.75 & 0.25 \\
\hline Landrace & 87 & 52 & 27 & 8 & 0.75 & 0.25 \\
\hline Dingyuan black & 71 & 55 & 16 & 0 & 0.89 & 0.11 \\
\hline
\end{tabular}

Table 3: Association analysis of the SNP genotypes of IRF6 gene with immune traits in three pig populations

\begin{tabular}{|c|c|c|c|c|}
\hline \multirow[b]{2}{*}{ Traits } & \multicolumn{4}{|c|}{ Genotypes (Least sequare mean \pm Standard error) } \\
\hline & $\mathrm{GG}(\mathrm{n}=165)$ & $\mathrm{GC}(\mathrm{n}=68)$ & $\mathrm{CC}(\mathrm{n}=19)$ & p-value \\
\hline IFN- $\gamma($ day 20) & $30.12 \pm 4.52^{\mathrm{A}}$ & $93.08 \pm 8.45^{\mathrm{B}}$ & $100.84 \pm 31.66^{\mathrm{B}}$ & 0.0264 \\
\hline IL-10 (day 20) & $147.32 \pm 14.74^{a}$ & $145.61 \pm 27.91^{\mathrm{a}}$ & $90.65 \pm 43.23^{b}$ & 0.0238 \\
\hline $\begin{array}{l}\mathrm{IFN}-\gamma / \mathbb{L}-10 \\
(\text { day } 20)\end{array}$ & $0.85 \pm 0.16^{\mathrm{a}}$ & $1.57 \pm 0.33^{b}$ & $1.16 \pm 1.310^{b}$ & 0.0341 \\
\hline
\end{tabular}

identified SNP has effects on immune traits in three pig populations. Results showed that the p-value of the SNP (HQ026023:1383 G>C) of IRF6 gene on level of IFN- $\gamma$ and IL10 (day 20 ) in serum were $0.0264,0.0238$, respectively and for the ratio of IFN- $\gamma$ to IL10 (day 20) in serum, the P achieved 0.0341 (Table 3 ) which all indicated significant. In the further analysis, researchers can also know that IFN- $\gamma$ and IL10 level in serum of pigs associated with GG genotype were significantly higher than with $\mathrm{CC}$ genotype $(\mathrm{p}<0.05)$ but ratio of IFN- $\gamma$ to IL10 with CC genotype were significantly higher than those of pigs with GG genotype $(\mathrm{p}<0.05)$. As reported, the capacity to activate or inhibit monocytic and $\mathrm{T}$ lymphocytic functions could be reflected by the ratio of IFN- $\gamma / \mathrm{IL}-10$ production and a higher ratio has also been shown to have relevance with depressive disorders (Maes, 1999).

In the study, the ratio of IFN- $\gamma$ to IL-10 of Dingyuan Black pig was lower; this could be explained as the Chinese indigenous breed may have better $\mathrm{T}$ lymphocytic balance and immune capacity than western commercial pig breeds. Besides, the results also implied us that genetic background is one of the most important factors that influence the immune capacity.
IRF6 plays an important role in initiating cellular interferon-stimulated gene-mediated antiviral responses and in the transforming growth factor- $\beta$ signaling pathway. Moreover, this gene is essential for the development of the lip and palate and involved in development of the skin and external genitalia. While mutations in IRF6 gene are pathogenic for both Van der Woud Syndromes (VWS) and Popliteal Pterygium Syndrome (PPS). Until now, two missense mutations in the IRF6 gene had been identified in two Japanese families with PPS (Matsuzawa et al., 2010). Which may affect splicing in the IRF6 gene associated with VWS were also reported by Scioletti et al. (2010). For pig, another INF Regulatory Factor (IRF1) has been reported significantly associated with cytokine traits (Liu et al., 2009, 2011). While in the study, the SNP (HQ026023:1383 G>C) in exon7 of IRF6 was not missense mutation or to induce amino acid substitution. However, the synonymous SNPs also pay an important role in biological function. In some documents, these SNPs have been reported can affect protein expression by alteration or increasing the stability of the mRNA (Capon et al., 2004) and a silent polymorphism can also act on substrate specificity (Kimchi-Sarfaty et al., 2007).

As the immune system plays an essential role in disease resistance of animals, genes involved in the response of immune system could be regarded as the candidate genes for selection. The results provided a straightforward insight that IRF6 could be served as a genetic marker gene for immune traits which effects on IFN- $\gamma$, IL-10 and ratio of IFN- $\gamma$ to IL-10 in serum. However, the number of pigs analyzed in the study was restricted thus result in limitations to the results. Further investigation is needed to confirm the relationships between the SNP with immune traits among other pig populations.

\section{CONCLUSION}

In this study, one SNP of the IRF6 gene was identified by PCR-RFLP method. After the further association analysis between the SNP and immune traits, researchers can know that the SNP of IRF6 gene was significantly associated with IFN- $\gamma$ to IL-10 level of serum in 252 pigs in three pig populations. Generally speaking, the IRFG gene identified in the study should be regarded as a candidate gene for marker-assist selection in porcine disease resistance breeding program. These results could also possibly provide a foundation for further studies on IRF6 gene in pigs. 


\section{ACKNOWLEDGEMENT}

This research was supported by Scientific Technology Plan of Education Department of Anhui province, P.R. China (Grand No.2006KJ034C).

\section{REFERENCES}

Capon, F., M.H. Allen, M. Ameen, A.D. Burden, D. Tillman, J.N. Barkerand and R.C. Trembath, 2004. A synonymous SNP of the corneodesmosin gene leads to increased mRNA stability and demonstrates association with psoriasis across diverse ethnic groups. Hum. Mol. Genet, 13: $2361-2368$.

Kimchi-Sarfaty, C., J.M. Oh, I.W. Kim, Z.E. Sauna, A.M. Calcagno, S.V. Ambudkar and M.M. Gottesman, 2007. A silent polymorphism in the MDR1 gene changes substrate specificity. Sciences, 315: 525-528.

Liu, Y., X. Lu, Y.R. Luo, J.P. Zhou and X.Y. Liu et al., 2011. Molecular cloning and characterization of porcine interferon regulatory factor 1 (IRF1) gene. Mol. Biol. Rep., 38: 1901-1907.

Liu, Y., X. Lu, Y.R. Luo, J.P. Zhou, X.Y. Liu, Q. Zhang and Z.J. Yin, 2009. Effect of single nucleotide polymorphism of IRF1 gene on cytokine traits in three pig breeds. J. Anim. Vet. Adv., 18: 2346-2350.

Lohoff, M. and T.W. Mak, 2005. Roles of interferonregulatory factors in T-Helper-cell differentiation. Nat. Rev. Immunol., 5: 125-135.

Maes, M., 1999. Major depression and activation of the inflammatory response system. Adv. Exp. Med. Biol., 461 : 25-46.
Matsuzawa, N., S. Kondo, K. Shimozato, T. Nagao and M. Nakano et al., 2010. Two missense mutations of the IRF6 gene in two Japanese families with popliteal pterygium syndrome. Am. J. Med. Genet. A, 152: 2262-2267.

Nguyen. H., J. Hiscott and P.M. Pitha, 1997. The growing family of interferon regulatory factors. Cytokine Growth Factor Rev., 8: 293-312.

Redpath, S., A. Angulo, N.R.J. Gascoigne and P. Ghazal, 1999. Murine cytomegalovirus Infection downregulates $\mathrm{MHC}$ class II expression on macrophages by induction of $\mathbb{L}-10$. J. Immunol., 162: 6701-6707.

Sambrook, J., E.F. Fritsch and T.A. Maniatis, 1989. Molecular Cloning: A Laboratory Manual. 2nd Edn., Cold Spring Harbor Laboratory Press, Cold Spring Harbor, New York, USA., ISBN-13: 9780879695774, pp: $21-51$.

Schoenborn, J.R. and C.B. Wilson, 2007. Regulation of interferon-ã during innate and adaptive immune responses. Adv. Immunol., 96: 41-101.

Scioletti, A.P., F. Brancati, V. Gatta, I. Antonucci and B. Peissel et al., 2010. Two novel mutations affecting splicing in the IRF6 gene associated with van der Woude syndrome. J. Craniofac. Surg., 21: 1654-1656.

Taniguchi, T., H. Harada and M. Lamphier, 1995. Regulation of the interferon system and cell growth by the IRF transcription factors. J. Cancer Res. Clin. Oncol., 121: 516-520.

Taniguchi, T., K. Ogasawara, A. Takaoka and N. Tanaka, 2001. IRF family of transcription factors as regulators of host defense. Annu. Rev. Immunol., 19: 623-655. 